\title{
The Development of Language in Twins I. A Comparison of Twins and Single Children ${ }^{1}$
}

\author{
ELla J. Day
}

\section{INTRODUCTION}

$I^{\prime}$

N THE year 1886, Horatio Hale (17) in a paper published in the Proceedings of the American Association for the Advancement of Science, reported the case of a pair of twin boys who were so retarded in speech that members of the family could not understand them. These children lived in Boston in 1860 . According to the report of an aunt, who visited them frequently, they developed a twin language so unlike English that they could not be sent to school because no one could understand them. Observation of the occasional development of such a special language by twins, suggested the problem of research undertaken here. The twin situation is, from an environmental point of view, quite unlike that of single children and it seemed possible that this might be a factor of considerable significance in the development of language.

${ }^{1}$ From the Institute of Child Welfare, the University of Minnesota, The Development of Language in Twins, Part II, The Development of Twins: Their Resemblances and Differences will appear in a subsequent issue. This will include a discussion of the mental development of twins, and a comparison of the types of twins in intelligence, language development and certain physical traits.
McCarthy's (13) investigation "The Language Development of the Preschool Child" provided an excellent basis for comparison. This study was completed in the summer of 1928 at the Institute of Child Welfare of the University of Minnesota. Dr. McCarthy selected 140 children (20 at each 6 months age level from 18 to 54 months) on the basis of sex and socio-economic status. She visited them and recorded 50 consecutive rèsponses made by each child while he played with a group of toys that she presented to stimulate speech. These data were than analyzed in four different ways: by mean length of response; according to the Piaget functional analysis; by the grammatical construction of the sentence; and a word analysis by parts of speech. In brief the results indicated the developmental changes with age in agreement with other studies, as well as sex differences in favor of the girls. Differences in favor of the upper occupational groups were indicated also in each method of analysis. In the foreword to this study Dr. John E. Anderson says "On the basis of the number of controls utilized in the selecting of subjects and the care and thoroughness with which the data are analyzed, this monograph stands out as one of the best studies 
of the development of language which has yet appeared." Thus the present investigation was planned to repeat the McCarthy technique using twins.

\section{PURPOSE}

The purpose of this investigation was to compare the development of language in twins with that of singletons of the same ages, sex, and socioeconomic status.
2, 3, 4 and 5 years. Since McCarthy reports that 74 per cent of the responses of the 18 months old children were incomprehensible, it seemed adequate from the standpoint of the methods of analysis to be used, to begin with the 2 year age group. The wisdom of carrying the group on through the fifth year was not so apparent at the time the selection was made as the results now show it to be. An equal number

TABLE 1

Distribution of cases by age, sex and occupational class

\begin{tabular}{|c|c|c|c|c|c|c|c|c|c|c|c|c|}
\hline \multirow{2}{*}{$\begin{array}{l}\text { OCCUPATIONAL } \\
\text { CLASS }\end{array}$} & \multicolumn{2}{|c|}{2 YEARS } & \multicolumn{2}{|c|}{3 YEARS } & \multicolumn{2}{|c|}{$4 \mathrm{YEARS}$} & \multicolumn{2}{|c|}{5 Y EARS } & \multirow{2}{*}{ 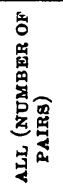 } & \multirow[b]{2}{*}{ 变 } & \multirow{2}{*}{ 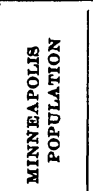 } & \multirow{2}{*}{ 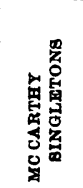 } \\
\hline & ڤ્ळ & 罚 & 悹 & 恋 & 旁 & 兑 & 宮 & $\sum_{0}^{\infty}$ & & & & \\
\hline & & & & & & & & & & per cent & per cent & per cent \\
\hline I & 1 & 1 & 2 & 0 & 0 & 2 & 1 & 1 & 4 & 5.0 & 5.4 & 5.0 \\
\hline II & 2 & 0 & 1 & 1 & 0 & 2 & 0 & 2 & 4 & 5.0 & 6.3 & 6.4 \\
\hline III & 7 & 9 & 8 & 8 & 10 & 6 & 9 & 7 & 32 & 40.0 & 37.3 & 35.7 \\
\hline IV & 6 & 4 & 4 & 6 & 4 & 6 & 3 & 5 & 19 & 23.8 & 24.3 & 25.7 \\
\hline V & 2 & 4 & 3 & 3 & 1 & 5 & 3 & 5 & 13 & 16.2 & 14.9 & 15.7 \\
\hline VI & 2 & 2 & 2 & 2 & 4 & 0 & 4 & 0 & 8 & 10.0 & 11.8 & 11.4 \\
\hline Total.. & 20 & 20 & 20 & 20 & 19 & 21 & 20 & 20 & 80 & 100.0 & 100.0 & 100.0 \\
\hline
\end{tabular}

SELECTION OF CASES

Through the courtesy of the Minneapolis and St. Paul Departments of Health, the writer had access to the birth registrations. The date of birth, sex, place of birth, name of physician attending the birth and the father's name, address and occupation were all recorded on the registration cards.

\section{Subjects}

Age and sex. After consideration of the findings of the McCarthy study, it was decided to select 80 pairs of twins, 20 pairs at each of four age levels, of boys and girls at each age were selected except at age four (see table 1) where there are 19 boys and 21 girls. These age groups are discrete because the records were taken within one month of the birthday. With the exception of one case where the records of the two children were not taken on the same day, the greatest deviation from the birthday was 38 days and the mean deviation for the whole group was 19.69 days. The one exception referred to deviated 99 days from the birthday.

Socio-economic status. The importance of securing a representative 
sampling of the population is clearly brought out in such studies as the McCarthy study and the Goodenough (9) evaluation of the Kuhlman-Binet tests for children of pre-school ages. The sampling was made according to the Goodenough (10) classification of the Minneapolis population which was based on the application of the Barr Scale for Occupational Intelligence and the Taussig industrial classification to the 1920 census report of the occupations of males in Minneapolis between the ages of 21 and 45 years. The occupational levels are grouped into a sixfold classification. Group I consists of the professional vocations; group II the managerial occupations; group III the retailers, salesmen and skilled workmen; group IV the semi-skilled workmen; group $\mathrm{V}$ the drivers, helpers, etc.; group VI the day laborers. Table 1 shows the percentage of each occupational class found in the Minneapolis population and the percentages represented by the twins and singletons.

The distribution of the sexes is not equal at each occupational class but is equal in the upper three and lower three classes at each age, except at age four.

\section{METHOD OF OBSERVATION}

The language record

Just as the selection of cases was made on a basis similar to that used in the McCarthy study, the technique of obtaining the language record was carried out as it was with the singletons. A group of toys consisting of two linenette picture books, one of familiar animals and one of Mother Goose, a very small automobile, a rubber ball, a pasteboard cat that meowed when squeezed, a telephone with a bell, and a small music box were shown to the children to stimulate speech. In so far as possible, McCarthy's toys were duplicated exactly. The examiner requested to see each child alone but this was not always possible. The children were permitted to open the suitcase and look at the toys as they wished. The examiner remained out of the situation as much as possible because spontaneous responses were desired. Some conversations between the examiner and the child however always occurred. When members of the family insisted upon remaining in the room, they sometimes facilitated spontaneous speech on the part of the twin and sometimes interfered with obtaining an accurate record.

Fifty consecutive verbal responses were recorded and the time noted. The responses were recorded exactly as they sounded to the examiner. A response was denoted as complete when a distinct pause occurred. A complete sentence was always considered as a single response, although a single response might be either a complete or incomplete sentence. The mean time for obtaining such a record was 14.9 minutes for the twins as compared with 19.3 minutes for the singletons. The shorter time required by the twins is probably due to two factors. In the first place, they said considerably fewer words in the fifty responses. In the second place, the examiner was in the home anywhere from one to two and a half hours and at least one of the children had a somewhat greater opportunity to become adjusted to the presence of a stranger. 
The examiner practiced taking such records with a group of children attending the nursery school at the University of Minnesota, preliminary to taking any records with the twins. She also had the advantage of being able to talk with Dr. McCarthy frequently and so check on minor differences in procedure.

\section{The Intelligence tests}

The Goodenough (18) drawing test of intelligence was given by the examiner to all the twins. This test consists merely in having the child draw a man. It is non-verbal and very simple to give. The results however were not useable since such a large percentage of the twins had not manipulated pencil and paper before and therefore they only scribbled.

The department of mental testing of the Institute of Child Welfare volunteered to give the twins the Minnesota Pre-school Scale, (11) which at this time was in the process of standardization. This test was devised by Goodenough and is a revision, for the most part, of the tests for these ages in the Kuhlman-Binet and the StanfordBinet tests. Test results were obtained on 123 of the 160 children. A full discussion of these results will be presented in Part II.

\section{METHODS OF ANALYSIS}

McCarthy's methods of analysis were duplicated exactly. A total of 7,836 responses were made and of these 7,156 or 90 per cent were comprehensible and 780 or 10 per cent were classed as semi-comprehensible or incomprehensible.

\section{Length of response}

The comprehensible responses were analyzed first according to length of response. McCarthy set up the following arbitrary rules for this analysis:

(1) Contractions of subject and predicate like "it's" were scored as one word.

(2) Contractions of the verb and negative like "can't" were scored as single words.

(3) Hyphenated words and compound nouns functioning as single words like "Mother Goose" were scored as one word.

(4) Each part of a verbal combination was scored as a separate word.

(5) "Lookit" which occurred frequently was scored as one word if used alone although if followed by an object it counted as two words.

\section{Functional analysis}

According to Dewey the primary motive of language is to influence the activity of others. Young children in particular use language as it relates to their needs and give little heed to the adult usage of grammatical constructions and parts of speech. Piaget (16) working at the Institute Rousseau in Geneva developed such a functional classification which with slight revision was used by McCarthy:

A. Egocentric speech

1. Repetition or echolalia

2. Monologue

3. Dual or collective monologue

B. Socialized Speech

1. Adapted information

(a) Naming

(b) Remarks about the immediate situation

(c) Remarks associated with the situation

(d) Irrelevant remarks

2. Criticism 
3. Emotionally toned responses

4. Questions

5. Answers

6. Social Phrases

7. Dramatic imitation

\section{Construction analysis}

Until one undertakes the analysis of his own speech, or that of other adults, the extent to which adult speech falls short of grammatical standards of construction is scarcely realized. Many of the responses made in adult conversation are not structurally complete sentences, though because of what every adult knows to be implied, they are accepted in good everyday usage. The child patterns after the adults about him since as yet he is neither reading nor writing. For this reason McCarthy first divided the responses into the two groups complete and incomplete but included under the forms of complete sentences a group which were functionally complete but structurally incomplete. The outline of the classification used in this type of analysis is as follows:

A. Complete Responses

1. Functionally complete but structurally incomplete responses

2. Simple sentences without a phrase

3 . Simple sentences with a phrase

4. Compound sentences

5. Complex sentences

6. Elaborated sentence, two phrases, two clauses or a clause and a phrase

B. Incomplete Responses

1. Omission of the verb

2. Omission of the subject

3. Omission of a preposition

4. Omission of a conjunction

5. Omission of the verb and the subject

6. Miscellaneous omissions (itemized)
Word analysis

Neither the McCarthy investigation nor the present study are primarily studies of the child's vocabulary. The nature of the experimental situation itself controlled somewhat the words the child used. For instance, by far the largest proportion of nouns used were the names of the toys and pictures shown the child. However, because of the number of children, and their selection, as representative of the Minneapolis population, an analysis of the words, according to the parts of speech, seemed warranted from the standpoint of showing their relative use, in a sample of running conversation.

The rules adopted by McCarthy for determining the number of different words used are similar to those developed by Bateman (1): They are as follows:

1. Include no proper nouns.

2. Include no plural form unless the singular was not used.

3 . Include all forms of pronouns.

4. Include no variations of verbs or of adjectives unless they are from a different root.

5. The same word may be listed more than once according to its grammatical use; i.e., if a word is used as a noun and also as a verb, it is included twice.

\section{RELIABILITY}

\section{Method of observation}

In order to get some estimate of the degree of accuracy in recording such a verbal record, Dr. McCarthy, the examiner, and one other observer took records simultaneously, 25 responses 
in length, on 10, two to five year old children, from a settlement house.

Table 2 shows the coefficients of reliability found between each two observers. The examiner first analyzed the language records as to length of response, the functional classification, and the construction of sentence category, just as the original data had been treated. The Spearman method of rank differences was used to determine the coefficients of reliability. In length of response the mean for each child according to each observer was
COMPARISON OF DATA ON LENGTH OF RESPONSE: TWINS AND SINGLETONS CHRONOLOGICAL AGE

The mean length of response is based upon a distribution of the responses. varying in length from one to nineteen words rather than upon a distribution of each child's mean length of response. Figure 1 shows a surprising difference in rate of language development for twins and singletons. At two years the difference is small but appears to become increasingly greater with age

TABLE 2

Reliability coefficients on the method of recording

\begin{tabular}{|c|c|c|c|c|}
\hline & \multicolumn{4}{|c|}{ OBSERVERS } \\
\hline & 1 and 2 & 1 and 3 & 2 and 3 & $\begin{array}{c}\text { Mean of } \\
\text { all }\end{array}$ \\
\hline Mean length of response. & $\begin{array}{l}p \\
.98\end{array}$ & $\begin{array}{c}p \\
.99\end{array}$ & $\begin{array}{c}p \\
.99\end{array}$ & $\begin{array}{c}p \\
.99\end{array}$ \\
\hline 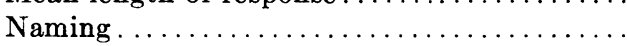 & .90 & .99 & .94 & .94 \\
\hline Remarks about immediate situation........ & .95 & .87 & .94 & .92 \\
\hline $\begin{array}{l}\text { Functionally complete but structurally in- } \\
\text { complete } \ldots \ldots \ldots \ldots \ldots \ldots \ldots \ldots \ldots \ldots \ldots\end{array}$ & .92 & .91 & .99 & .94 \\
\hline Simple sentences. . . . . . . . . . . . . . . . & .32 & .69 & .72 & .57 \\
\hline Incomplete sentences $\ldots \ldots \ldots \ldots \ldots \ldots$ & .65 & .40 & .87 & .64 \\
\hline
\end{tabular}

used for the correlation and in the other analyses the percentage of whatever item was being correlated was used.

These coefficients seem sufficiently high to indicate reliability of the method of recording.

\section{Methods of analysis}

The reliability of the various methods of analysis used in treating the language records was not determined in this investigation since McCarthy had determined this and found it to be high. and is consistently in favor of the singletons. The mean length of response for the five year old twins is slightly below that of the three year old singletons. A retardation of two years in language development, one would think, was a serious handicap since contacts with our fellowmen depend so largely upon our ability to make ourselves understood verbally.

Critical ratios $\mathrm{D} / \sigma_{\mathrm{D}}$, computed for each age level were high and increased with age. At two years the ratio was 4.9 ; at $3,11.6$; and at 4, 15.3. Hence the superiority of singletons to twins in 
language development is highly signifcant statistically.

Smith's investigation (18) of the development of the sentence and the extent of vocabulary in young children agrees very closely with the McCarthy results, and so only further emphasizes the handicap of the twins. The most rapid gain in length of response is made between two and three years by both twins and singletons. Although twins to when the curve of development for the twins turns and reaches the level of that of the singletons. Does the greater contact with other children, which occurs upon entrance in school, at or soon after the fifth year, stimulate language development sufficiently to give the twins this needed spurt? Does the twin situation so limit the child's environment in the early years of rapid development that he is always

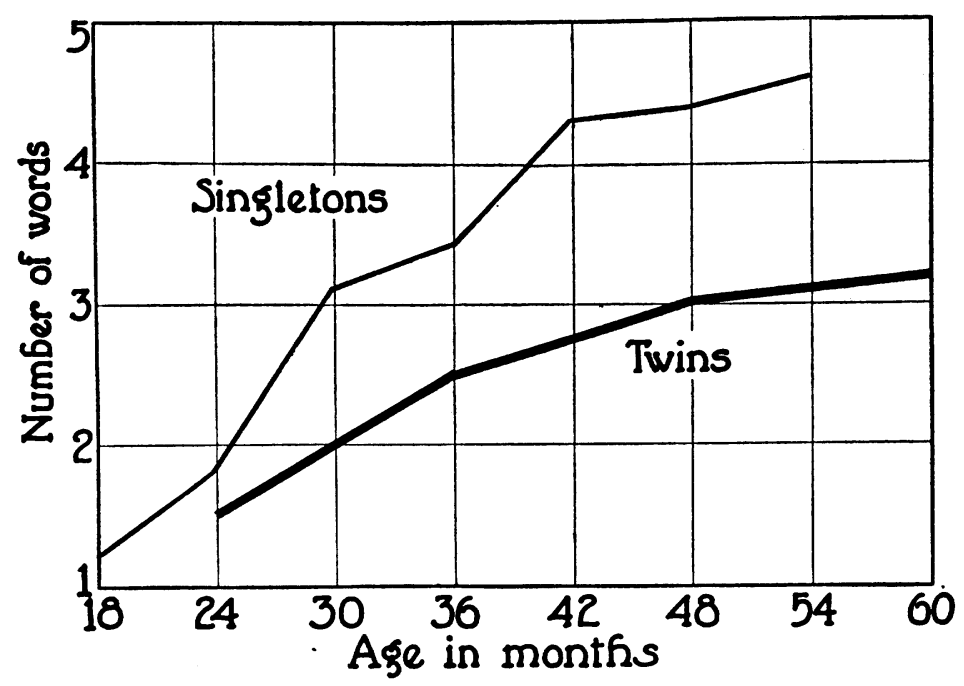

Fig. 1. Mean Length of Response of Singletons and Twins by Chronological Age

gain only one word in the entire year, singletons gain more than one word in the first half of the year. This difference in rate of development remains relatively the same up to five years. Smith feels that the relatively little gain in length of sentence after four or four and one-half years indicates that the sentence length has little value as a measure of sentence development after this age.

The question immediately arises as at a disadvantage? What is responsible for the retardation, heredity or environment, or both?

All of these questions and many more are as yet unanswered. Nevertheless the author has attempted to get what evidence she could to throw light on the problem.

Part II is devoted to a discussion of the mental ability of the twins but attention may be called at this time to the fact that the mental ability as well 
as the language development of the twin group appears to be below average. The mean I. Q. for the whole group is 94. This is based upon the results of the Minnesota Pre-school Scale. The singletons, with whom the twins are compared have a mean I. Q. of 103.3, after the correction recommended by Goodenough has been applied. This correction is a subtraction due to Goodenough's observation that mal phenomenon rather than a matter of selection.

\section{SEX DIFFERENCES}

In agreement with the findings of McCarthy, Nice (15), Gale (6), Mead (14), Terman (20), and Doran (4), this reveals sex differences in favor of the girls. (See figure 2.) These differences are less marked than in the group of singletons at every age except

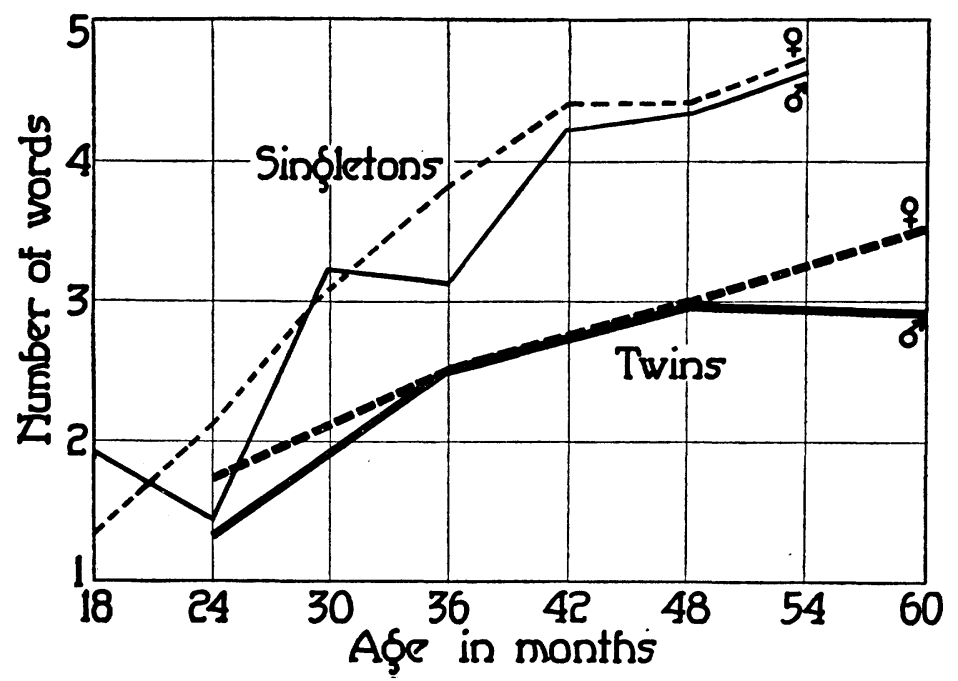

Fig. 2. Mean Length of Response of Singletons and Twins by Sex and Chronological Age

the Kuhlman-Binet test (the test used for the singletons) tended to score too high at the early ages. The singletons then appear to have been a group slightly superior even though they were so carefully selected. Had they been an average group the differences would be slightly decreased. That the twin group deviates even farther from normal is quite true although the evidence seems to be that this is a nor- four years, but are consistently in the same direction. It may be noted that at two years the twin girls are slightly superior to the single boys. The twin boys make a greater gain between two and three years than do twin girls but gain less thereafter. The differences between twin boys and girls at five years is greater than at any other age, while the greatest differences between the sexes in singletons was found at 
two and three years. Smith does not report a consistent sex difference.

\section{PATERNAL OCCUPATION}

Because of the unequal number of cases in each of the six occupational classes the differences between occupational classes is most fairly shown by dividing the age groups into the upper findings that the age groups become $18,27,39$ and 51 months, rather than at the exact year levels of the twins. The differences between twins and singletons are even more striking when based upon distribution by occupational class. That the singletons of the lower occupational groups are consistently above the twins of the upper

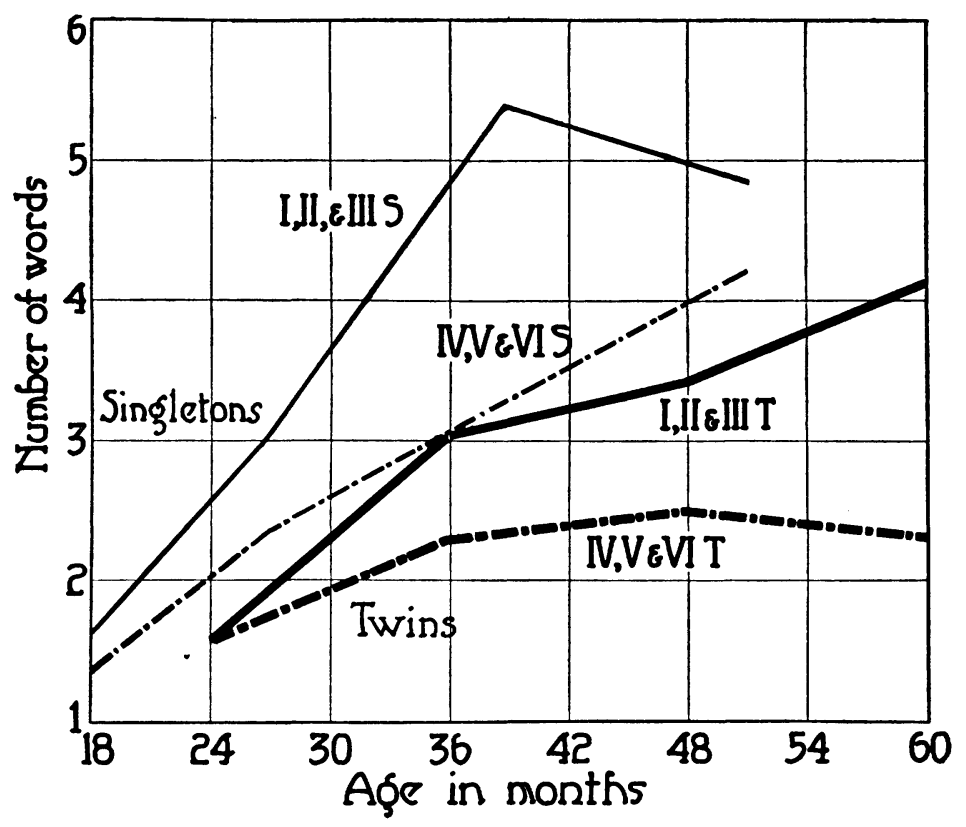

Fig. 3. Mean Length of Response of Singlietons and Twins by Upper and Lower Occupational Groups and Chronological Age

three and lower three occupational classes. By so doing an equal number of cases and an equal number of each sex appears in each group. Figure 3 shows the expected differences between these groups. In comparing these results with the McCarthy results it must be noted that the age groups are not strictly comparable. The singletons were so grouped in reporting these groups presents a surprising picture of retardation. The mean of the differences at each age between upper and lower groups is .90 words for the singletons, .85 words for the twins so that the differences between upper and lower groups remain relatively the same. The fanning out of curves of the upper and lower group twins indicates that the difference increases with age, which 
suggests that environment plays a rôle in this.

COMPARISON OF DATA ON FUNCTIONAL ANALYSIS; TWINS AND SINGLETONS

The percentage of responses of the Junctional classification were worked
When considered from the standpoint of age groups the incomprehensible responses, though somewhat fewer for twins at two years are slightly greater at three and four years and are still in evidence at five years. With the marked retardation in language
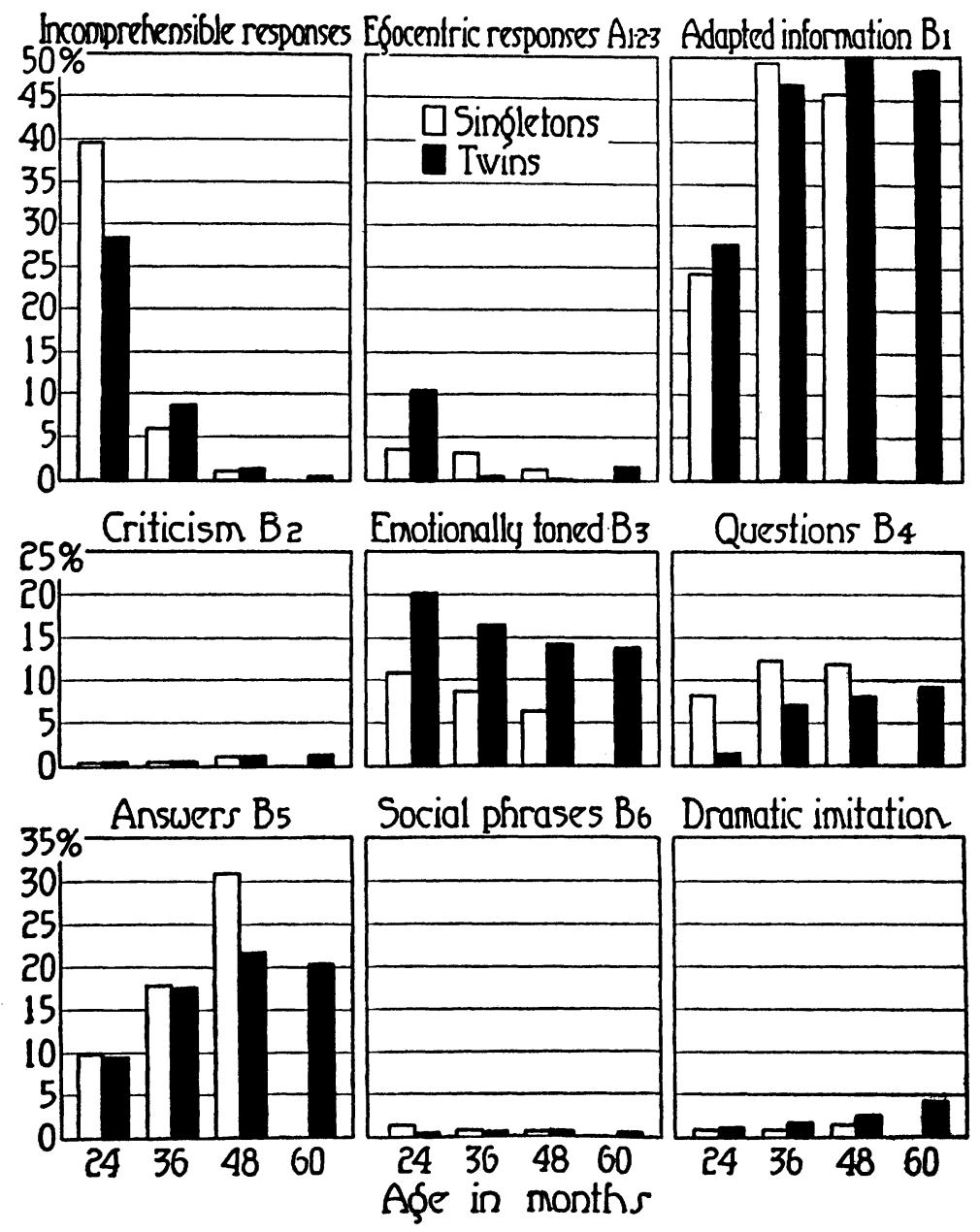

Fig. 4. Functional Analysis of Singletons and Twins by Chronological Age

out both inclusive and exclusive of the incomprehensible responses. Figure 4 shows the percentages of this classification based on all responses, including the incomprehensible responses. development indicated by the differences in mean length of response of twins and single children, one might expect a very much greater percentage of incomprehensible responses on the 
part of the twin. Such responses do seem to persist for a longer time in the twins, however, which is suggestive of a slower development. Two factors in the twin situation may have acted to reduce somewhat the percentage of incomprehensible responses. It may be easier to understand short statements as compared with long ones and the twin data are composed of many more single word responses. Also, the examiner had had, just previous to making this study, two and one half years nursery school experience and was quite accustomed to interpreting the speech of young children. Dr. McCarthy on the other hand had had only the contact any adult may have with children previous to collecting her data.

The 780 incomprehensible responses include 83 semicomprehensible responses. Of 697 responses actually incomprehensible 287 or 41 per cent were single syllables, 121 or 17 per cent repetition of the same syllable and 289 or 42 per cent a series of different syllables. At two and three years the single syllables slightly exceed the others in number. At four and five years the series of different syllables is in the lead, in fact at five years, it is the only one represented. This type of incomprehensible response is no doubt a poor attempt at adult speech but the single syllables and repetition of the same syllable may be the voice play similar to that practiced by the young infant.

The three types of ego-centric responses described by Piaget are grouped together because each one appears to such a small extent. The twins, though they show more of this type of speech than the singletons at two years, show considerable less at three and four years, with an increase at five years. The twin situation of constant companionship, one might expect, would not be conducive to extensive ego-centric speech but rather to socialized forms of speech.

The different types of socialized speech are best presented in figure 5 where adapted information is divided into its sub-heads of naming, remarks about the immediate situation, remarks associated with the situation, and irrelevant remarks. Here too all percentages appear slightly increased since they are based upon comprehensible responses only.

Though as a whole adapted information shows increase with age and percentages in fairly close agreement with the singletons, when the four types of adapted information are considered separately differences between twins and singletons show up. Naming, the first type scarcely shows any decrease while with the singletons there is a marked decrease. That this function of language, typical of the two year old singletons but not so much so of the four year olds, persists through five years in the twins is indicative of maintenance of early language habits after they should have been dropped.

Remarks about the immediate situation increase with age but are present in greater numbers in twins than in singletons, whereas remarks associated with the situation are very few in number as compared with singletons, show relatively no increase with age, and do not appear at all until three years. In consideration of these two differences, one may wonder whether the limitations of the twin environment may account for these differences. 

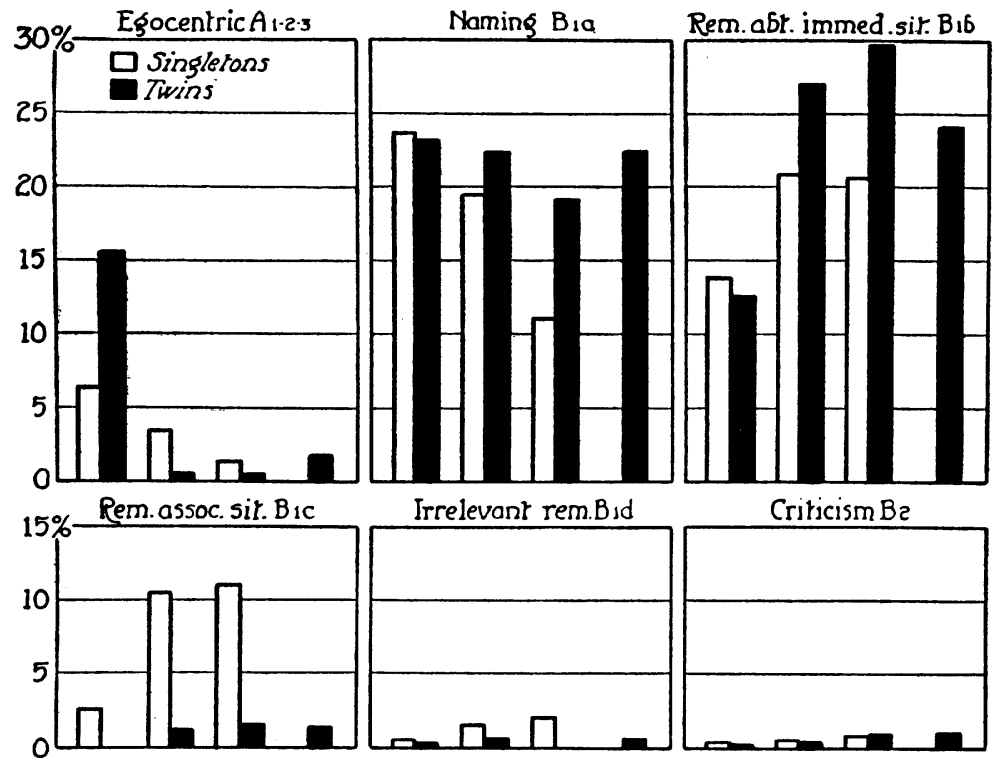

Irrelevant rem.Bud

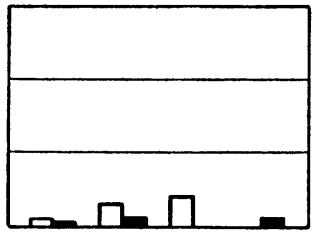

Criticism Bz

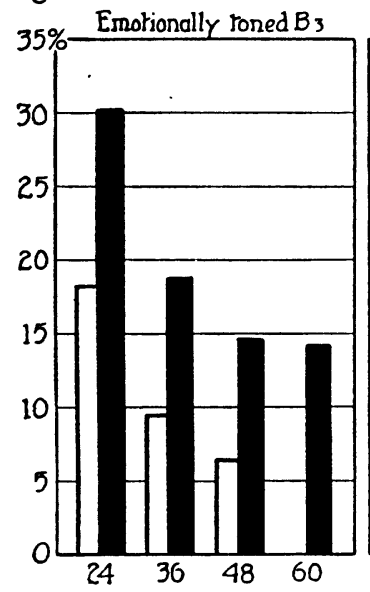

Questions B4
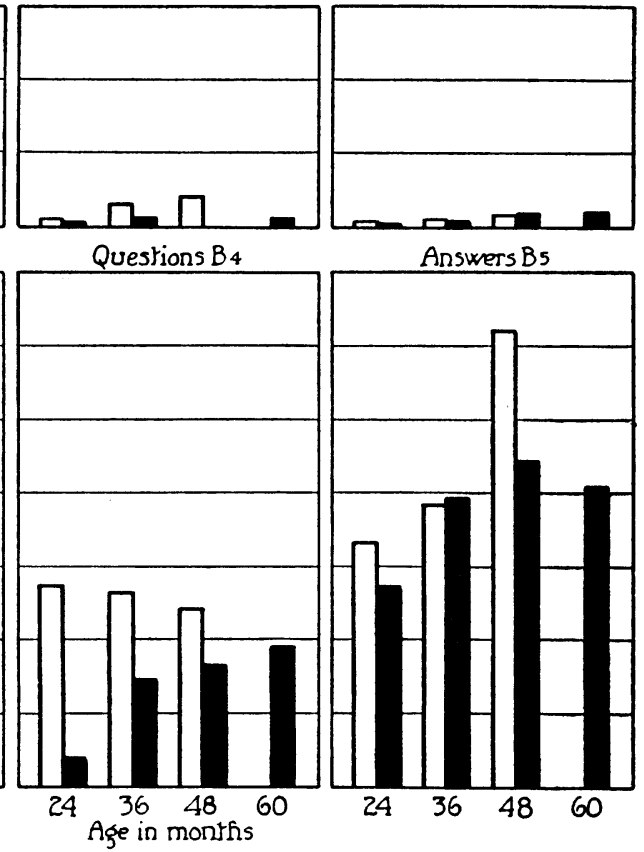

Answets Bs
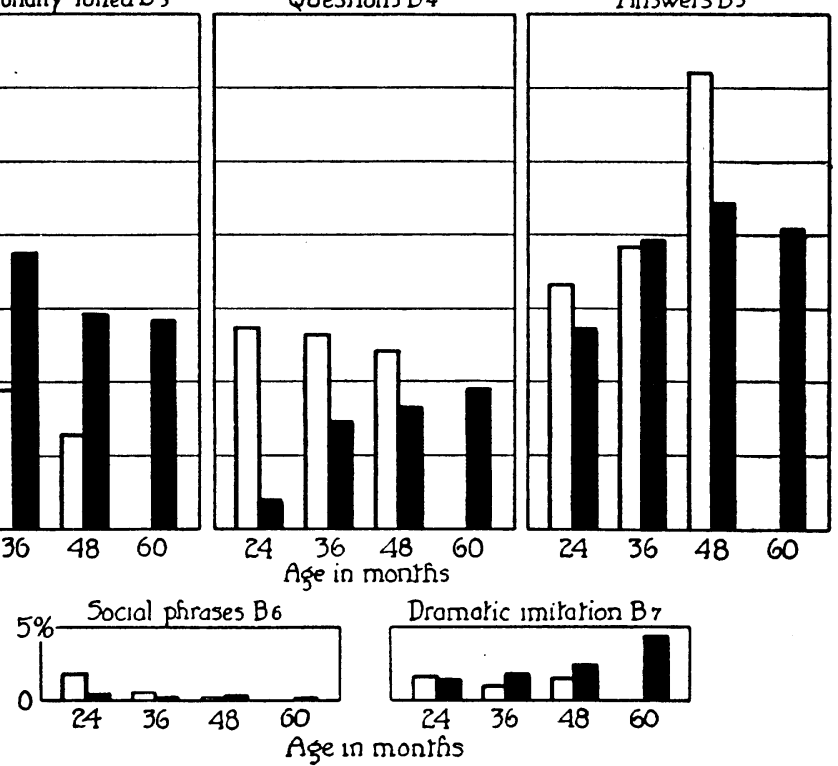

Fig. 5. Functional Analysis of Singletons and Twins by Chronological Age (Based on Comprehensible Responses)

The percentages of irrelevant remarks are comparatively insignificant. The singletons show a slight increase with age, however, which the twins do not show.
Criticism shows close agreement between twins and singletons and does increase with age.

The emotionally toned responses show one of the most striking differ- 
ences between the two groups. Twins have almost double the per cent of the singletons at every age. Both show a decrease with age. This, like naming, is suggestive perhaps of persistence of infantile habits of language.

Questions increase with age in the twins but even at five years have not attained the per cent shown by singletons at two years. This no doubt is somewhat indicative of the retarded language development as well as of a high degree of satisfaction from companionship rather than from investigation of the environment.

Answers also increase with age but neither increase as much nor are present to so great an extent as with single children. This can not be attributed entirely to retarded development, however, since the extent to which the examiner asked the child questions determined to a considerable extent the percentage of answers given.

Social phrases though very much less at two years are slightly less at three years for twins than for singletons and greater at four years. Close companionship may be a factor here in reducing the need for such phrases.

Dramatic imitation increases very much with age and appears to be of greater significance in twins than in singletons. The social advantages of the twins through their companionship may bring this out somewhat more.

In considering the functional analysis as a whole it may be pointed out that the twins show retardation in those phases of the analysis which show the greatest developmental changes with age such as naming, emotionally toned responses, and questions. In ego-centric responses and dramatic imitation, however, they appear in advance of the singletons. These last two phases may easily be the result of close companionship.

As with the singletons, girl twins show some superiority over the boys in those items which make the greatest change with age. Comprehensive tables for these items are too detailed for publication. A large difference between boy and girl twins in incomprehensible responses at two years puts the girls quite inadvance of the boys. At three and four years the girls have a slightly greater percentage of incomprehensible responses, and at five they have less but these differences are so slight and the total percentage at three, four, and five years so small that the reversion is probably due to selection of cases.

The girls also show less ego-centric speech at every age except five years. The differences are small, however, except at two years, which is the most significant age from the standpoint of total percentage of this type of response.

In naming, the boy twins increase slightly while the girls decrease from the second to fourth year and then increase at five years. Girls have somewhat greater proportion of remarks about the situation and both boys and girls increase with age to four years then drop a bit at five years.

Girls increase more and are superior at all ages in remarks associated with the situation.

Emotionally toned responses are decidedly greater for the girls except at age three where a difference of only one per cent is in favor of the boys. The greatest differences in percentage of questions occurs at two years and is in favor of the girls. The other phases 
of the functional analysis though they show some differences between the sexes show no striking or consistent trends.

The chief phases of analysis which showed marked differences between the upper three and lower three occupational classes are incomprehensible responses, ego-centric speech, questions, and remarks about the immediate situation. The greatest difference in incomprehensible responses is at two years where the upper class twins show about one-half as great a proportion as the lower class. Just the reverse situation is found in ego-centric speech. The lower group have slightly less than twice as much as the upper group at two years, and have none at all at the other ages. This was also the case with the singletons, except at thirty-nine months, where the lower group exceeded the upper group by quite a large proportion. Perhaps the sampling is not sufficient for these differences to mean a great deal since the percentage at any age is not very great. In both questions and remarks about the immediate situation the differences are not so marked at two and three years but become increasingly so at four and five years. The lower group shows a smaller proportion of these than the upper groups. A similar situation was found with singletons in regard to questions but not in regard to the other phase.

COMPARISON OF DATA ON CONSTRUCTION ANALYSIS: TWINS AND SINGLETONS

\section{Chronological age}

Figure 6 again shows that twins are retarded in language development as compared with singletons. Since they were found so retarded when measured by length of response one could scarcely expect to find them using many of the more complex forms of the sentence. It may be said, however, that in general the same tendencies with age are indicated in both the twins and singletons.

The functionally complete and structurally incomplete responses though they decrease with age are present to a somewhat greater extent in twins than in singletons. This group as has been stated, consists very largely of the single word responses. Although such responses appear rather commonly in adult speech they appear there largely in conversational usage while the young children employ them in other ways. For instance, in looking through the picture books it was not uncommon for the children to point at and name objects, and use no sentence at all. Twins evidently maintain this rather infantile manner of talking about what they see longer than do single children.

The simple sentence and all other forms of complete sentences increase with age but at every age are present to a considerably less extent than they are in singletons. The more complex the form of the sentence the greater the relative differences between twins and singletons become.

Incomplete sentences while not always present to a greater extent than in singletons do not drop off as rapidly. This again indicates persistence of early modes of talking or of rather infantile language habits.

The sex differences in sentence structure are not as marked for twins as singletons. There is no consistent 

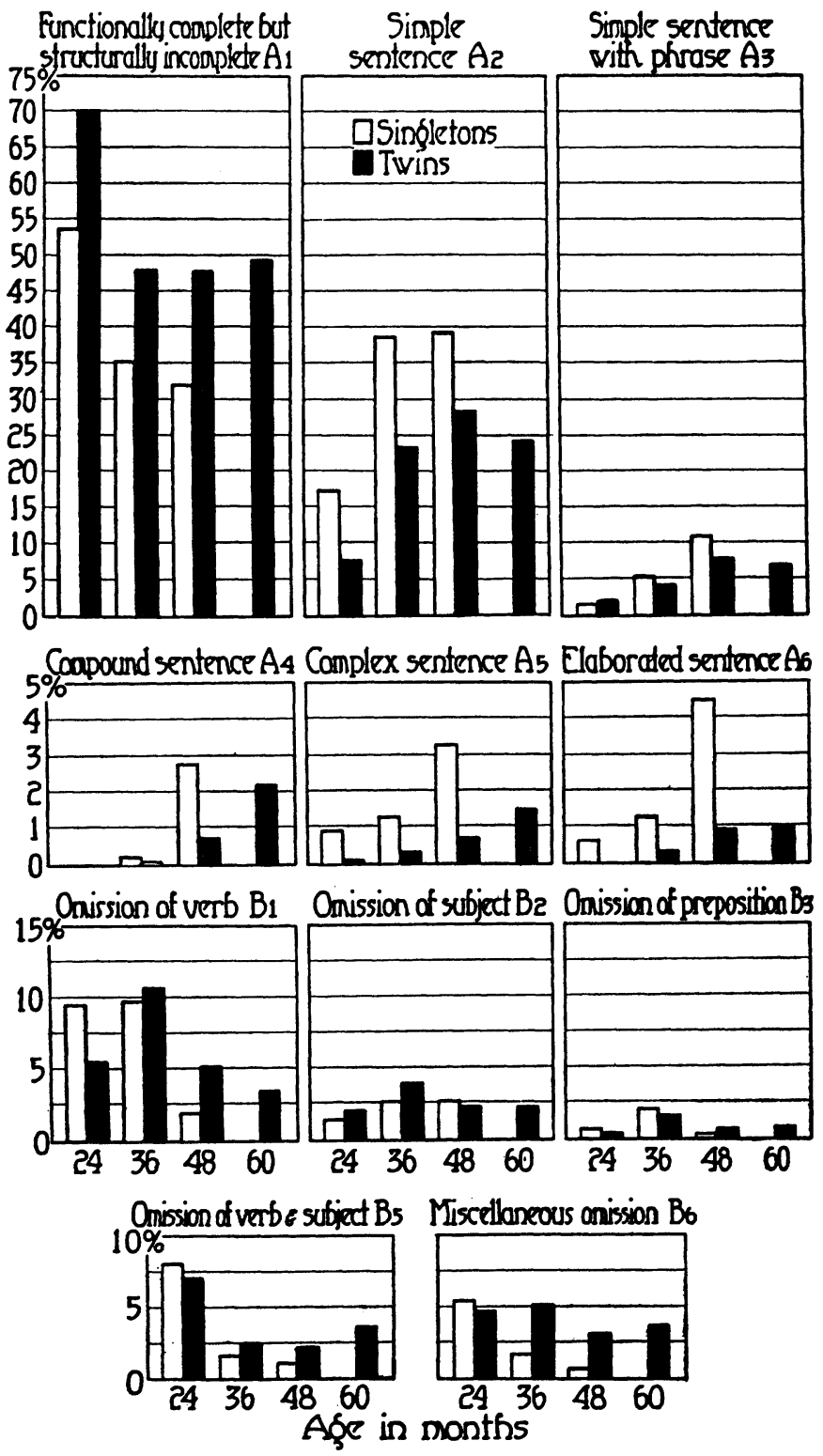

Fig. 6. Construction Analysis of Singletons and Twins by Chronological Age (EXClusive of INCOMPREhensible Response)

trend in the differences between the show all the forms of the complete boy and the girl twins in any of the items of the classification. It may be noted, however, that the girls do sentence earlier and in larger proportion than the boys. Probably these items show the most important de- 
velopmental changes with age and thus the girls may be considered in advance of the boys since they are using the more complex forms of the sentence earlier.

In relation to the singletons both boy and girl twins are retarded. In fact, as in the length of response, the girl twins rank below the boy singletons in practically all classifications of construction. Both sexes show the continuance of the functionally complete but structurally incomplete responses in much greater proportion than do singletons of the same age and sex.

When the responses are considered from the point of view of occupational class and construction of the sentence the differences are again found in favor of the upper groups.

The functionally complete but structurally incomplete responses are maintained in larger proportion through the fifth year by the lower groups and seem to indicate, as has been pointed out before, the continuance of a somewhat infantile habit of speech. All of the more complex forms of the sentence are present to a greater extent in twins from the upper groups than those from the lower groups. But as in the other analyses the upper group of twins is frequently below the lower group of singletons. In the comparison of two groups, however, it must be remembered that the singletons are so grouped that the age falls three months in advance of the age of the twins.

COMPARISON OF WORD ANALYSIS: TWINS AND SINGLETONS

These data were treated in two ways. Both the total ${ }^{\prime}$ number of words used by each child and the number of different words used by each child and each age group, were separated into the parts of speech.

Figure 7 shows the percentage of each part of speech of the total words used. Nouns show close agreement for twins and singletons both in the total percentage used and in the marked drop in percentage from two to three years. The percentage of verbs in which singletons show a gradual increase, from two to four years, is relatively much less at two years in twins, equal to the singletons at three years, and constant thereafter. Adjectives increase from approximately 2 per cent at two years to 8 per cent at five years, in twins. Singletons do not show this marked increase but even at two years have 10 per cent of adjectives, which exceeds the twin five year old percentage. Adverbs, except for a slight use at three years, are constant throughout and slightly greater in percentage in twins than in singletons. Pronouns increase with age to a greater extent in twins than singletons. They are, at every age, somewhat fewer in proportion. Con junctions are late in appearing. Girl singletons show a small per cent at eighteen months and the boys show none until thirty months. A smaller per cent (.9) appears at three years in the twins, and at five years the proportion is still smaller than that for singletons. Prepositions although they show a greater increase with age in twins than in singletons, at two are much less in proportion, the same at four years, and drop some at five years. Although interjections decrease with age markedly, the twins show a very much greater proportion at all ages, 
especially at two years, than do total words used by both singletons singletons. This, no doubt, is related and twins. This shows differences to the large porportion of emotionally similar to those in the mean length of toned responses which the twins response. The singletons have but a showed in the functional analysis, slight advantage at two years, but and like it, is somewhat indicative of maintenance of infantile language. show an increasing advantage with age. The 158 words attained by the twins at The miscellaneous parts of speech five years are equaled in number by
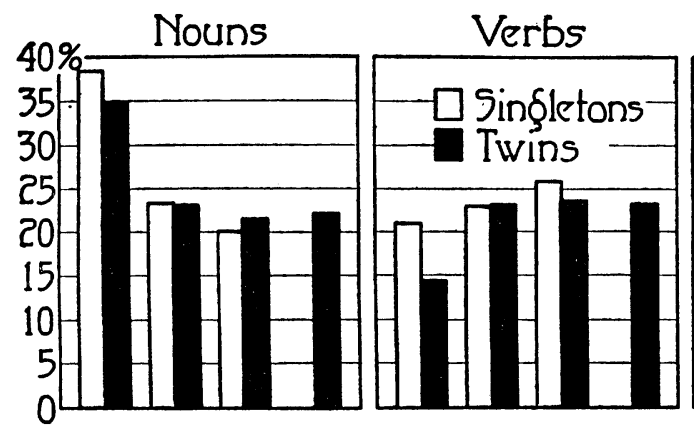

Adjectives

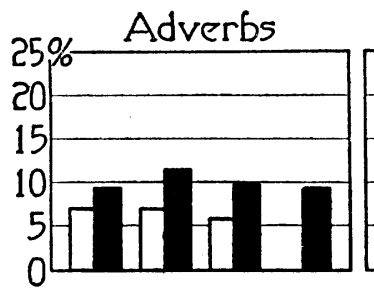

Pronouns
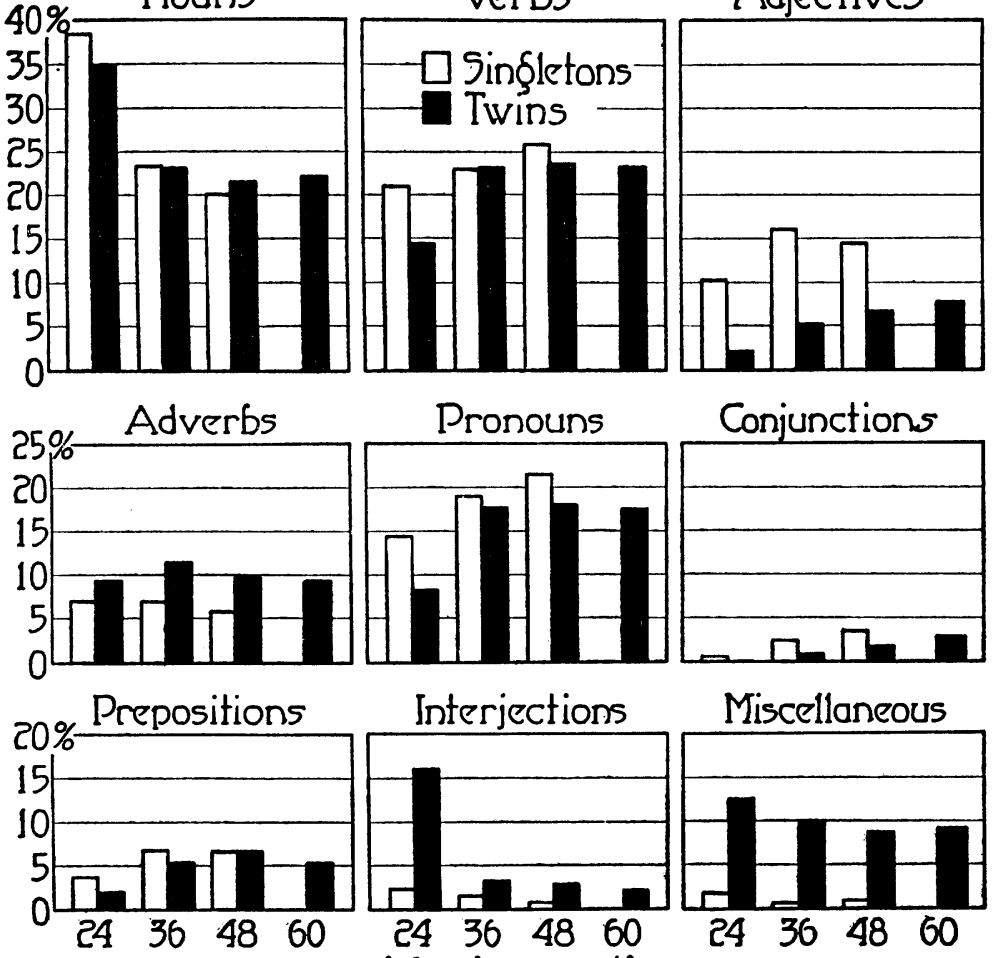

Conjunctions

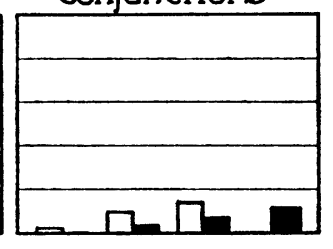

Miscellaneous

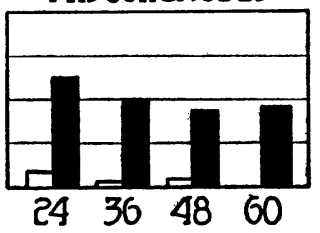

Ase in months

Fig. 7. Percentage of Parts of Speech Used by Chronological Age (Based on Total Words UsED)

include words which were difficult to classify more positively, such as "uhmuh," "uh-uhm" used so frequently for "yes" and "no". These appear to be used to a considerably greater extent by twins than by singletons. This then seems to show a tendency to attain adult standards more slowly.

Table 3 shows the mean number of the singletons between thirty and thirty-six months. The retardation at five years is equivalent to approximately two years.

The percentage of different words of each part of speech used by each age group are presented in figure 8 . It may be observed that the changes with age are not the same when considered 
from the standpoint of percentage of The percentage of verbs remains reladifferent words used. For instance, tively constant. Twins show a smaller the percentage of nouns remains rela- percentage of verbs than singletons at

TABLE 3

Mean number of words used by C.A. and sex

\begin{tabular}{|c|c|c|c|c|c|c|}
\hline \multirow{3}{*}{$\begin{array}{c}\text { CHRONO- } \\
\text { LOGICAL AGE }\end{array}$} & \multicolumn{6}{|c|}{ MEAN NUMBER OF TOTAL WORDS } \\
\hline & \multicolumn{3}{|c|}{ Singletons (Mc Carthy) } & \multicolumn{3}{|c|}{ Twins } \\
\hline & Boy & Girl & All & Boy & Girl & All \\
\hline $\begin{array}{c}\text { months } \\
24\end{array}$ & 36.8 & 87.1 & 66.0 & 40.11 & 70.9 & 55.90 \\
\hline 36 & 164.4 & 176.2 & 170.3 & 116.80 & 112.45 & 114.63 \\
\hline 48 & 213.4 & 218.5 & 216.3 & 146.31 & 146.00 & 146.15 \\
\hline 60 & & & & 143.30 & 173.20 & 158.25 \\
\hline
\end{tabular}
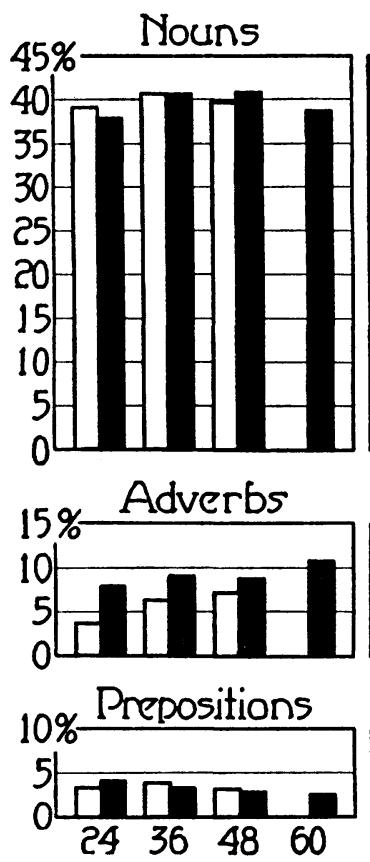

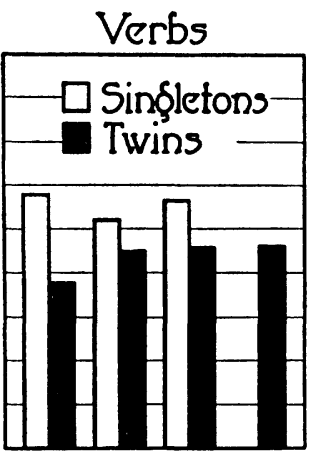

Pronouns

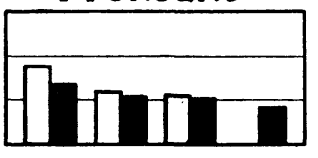

Interjections

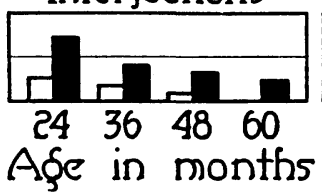

Adjectives

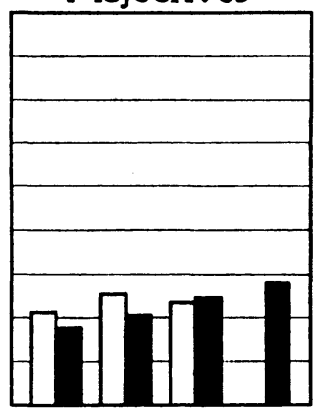

Conjunctions

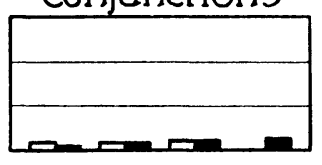

Miscellancous

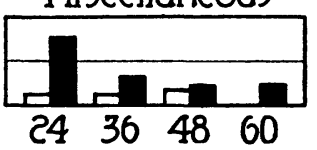

Fig. 8. Percentage of Parts of Speech Used by Chronological Age (Basedon Different Words Used at Each Age Group)

tively constant rather than decreasing all ages. Adjectives increase in perwith age. The child's vocabulary of centage slightly with age in both nouns is actually increasing with age. groups. The percentage of adverbs 
increases with age more in the singleton group than in the twin group. Pronouns decrease in percentage with age although the actual number after three years remains about constant. Conjunctions increase in percentage a little in both groups and agree closely in total percentages. The percentage of prepositions decreases with age in twins and remains constant in singletons. Interjections decrease in percentage with age. The twins, however, show even at five years, a percentage almost equal to the two year old singleton. The miscellaneous words decrease with age and are higher
Adverbs, interjections and verbs continue to show distinct differences. Twins show a greater percentage of adverbs and interjections and a smaller percentage of verbs.

The sex differences in percentage of parts of speech, of the total words used, are of the same order as in the singleton group although they are less in magnitude in most instances. Girls are in advance. The greatest differences appear at two years, indicating, perhaps the earlier linguistic maturity of the girls.

The total number of words used also favors the girls. As in the mean

TABLE 4

Mean number of different words used by twins and singletons

\begin{tabular}{|c|c|c|c|c|c|c|c|c|c|c|c|c|}
\hline \multirow{2}{*}{ YEARS } & \multicolumn{6}{|c|}{ TWINS } & \multicolumn{6}{|c|}{ SINGLETONS (MC CARTHY) } \\
\hline & $\begin{array}{c}\text { No } \\
\text { cases }\end{array}$ & Boys & $\begin{array}{c}\text { No } \\
\text { cases }\end{array}$ & Girls & $\begin{array}{c}\text { No } \\
\text { cases }\end{array}$ & All & $\begin{array}{c}\text { No } \\
\text { cases }\end{array}$ & Boys & $\begin{array}{c}\text { No } \\
\text { cases }\end{array}$ & Girls & $\begin{array}{c}\text { No } \\
\text { cases }\end{array}$ & All \\
\hline 2 & 19 & 16.4 & 20 & 24.2 & 39 & 20.4 & 8 & 16.6 & 12 & 37.3 & 20 & 29.1 \\
\hline 3 & 20 & 45.4 & 20 & 45.1 & 40 & 45.3 & 10 & 60.1 & 10 & 66.0 & 20 & 62.8 \\
\hline 4 & 19 & 59.1 & 21 & 56.1 & 40 & 56.5 & 9 & 91.1 & 11 & 93.8 & 20 & 92.6 \\
\hline 5 & 20 & 61.3 & 20 & 69.4 & 40 & 65.3 & & & & & & \\
\hline
\end{tabular}

in percentage for the twin group than for the singleton group.

The chief differences between singletons and twins in percentage of parts of speech used are in verbs, adjectives, pronouns, conjunctions and interjections. The twins differ from the singletons in showing a smaller percentage of verbs at two years, a smaller percentage of adjectives, pronouns and conjunctions at all ages, and a greater percentage of interjections at all ages. In the percentages of parts of speech of the different words, adjectives, pronouns and conjunctions do not show great differences in proportion between twins and singletons. length of responses, the boy and girl twins do not differ at three and four years although they show striking differences at two and five years. In the number of different words used (table 4) girls are superior at every age except three years, when the boys exceed by 19 words, the majority of which are verbs.

The twin group when divided into the upper and lower occupational classes shows differences similar to those found in the singletons. The upper group shows a superiority which is most marked at two years in those parts of speech of greatest developmental significance. This may in- 
dicate an earlier linguistic maturity of twins from the upper occupational classes.

Descoeudres (2), Drever (5), Gesell and Lord (7), Hertzer and Reindorf (12), Smith and McCarthy all have obtained results which agree in showing a positive relationship between linguistic development and socio-economic status. Stern (19) in reworking the Descoeudres data estimated the difference between educated and working class children to be equivalent to about 8 months in age.

\section{SUMMARY}

1. As compared to single children twins are retarded in language development, as measured by each of the methods of analysis used.

2. This language retardation increases with age, within the age period covered (2-5 years) and is most clearly shown in the comparison of the flndings of mean length of response.

3 . Both in the analysis according to the structure of the sentence, and in the world analysis, twins show the greatest retardation in those phases which make the greatest change with age.

4. This is also true in the functional analysis with the exception of two phases. Ego-centric responses and dramatic imitation, which are both affected, probably by the social advantage of the twin situation, show a superior development in twins as compared with singletons.

5. A small sex difference in favor of the girls appears in all methods of analysis. These sex differences are not as great as in the case of singletons, due possibly to the operation of the social factor.

6. Twins of the upper three occupational classes are superior in all methods of analysis to the twins of the lower three occupational classes.

7. Singletons of the lower three occupational classes are superior in mean length of response to the twins of the upper three occupational classes. They are frequently superior in the phases of the other analyses.

8. The twins in this study were found to be approximately ten points below the I.Q. of the slightly superior group of singletons with whom they were compared.

If in the twin situation each child has the other for a model in speech a large proportion of the time, rather than adults or older children as in the case of singletons, perhaps we may expected slower progress with a poorer model. Nothing in the situation prevents two children from listening simultaneously to what adults say, although the time spent in practicing speech might be limited and considerably reduced. In the first place only one person can talk at a time and in the second place perhaps the activities or even the presence of a twin provide some of the satisfaction otherwise obtained from conversation. Whatever the factors may be however, the evidence is clear that during the preschool years twins progress toward adult use of language at a relatively slow rate. 


\section{REFERENCES}

(1) Bateman, W. G.: Two children's progress in speech with detailed vocabularies. Jour. Educ. Psychol., 6, 1915, 475-493.

(2) Descoeudres, Alice: Le développement de l'enfant de deux à sept ans. Neuchâtel and Paris; Delachaux and Niestle, $331 \mathrm{pp}$.

(3) Dewey, J.: The psychology of infant language. Psychol. Rev., 1894, 1, 63-66.

(4) Doran, E.: A Study of Vocabularies. Ped. Sem., 1907, 14, 401-438.

(5) Drever, J.: The vocabulary of a free kindergarten child. Jour. Exper. Ped., 1919, 5, 28-37.

(6) Gale, M. C. and Gale, H.: The vocabularies of three children in one family at two and three years of age. Ped. Sem., 1902, 9, 422-435.

(7) Gesel, A. ANd Lord, E.: A psychological comparison of nursery-school children from homes of low and high economic status. Ped. Sem., 1927, 35, 339-356.

(8) Goodenough, Florence L.: Measurement of intelligence by drawings. World Book Co., 1926, pp. 177.

(9) Goodenough, Florence L.: The Kuhlman-Binet Tests for children of preschool age. A critical study and evaluation. University of Minnesota Press., pp. 146.

(10) Goodenough, F. L. and Anderson, J. E.: Experimental child study. The Century Co., pp. 546.

(11) Goodenough, F. L., Foster, J. C. and Van Wagenen, M. J.: Minnesota pre-school scale. Educational Test Bureau Inc., Minneapolis.
(12) Hertzer, H. and Reindorf, B.: Sprachentwicklung und soziales Milieu. Zsch. f. angew. Psychol., 1928, 29, 449-462.

(13) McCarthy, Dorothea A.: The language development of the pre-school child. University of Minnesota Institute of Child Welfare Monograph Series No. 4, Minneapolis, University of Minnesota Press, 1930, pp. 174.

(14) Mead, C. D.: The age of walking and talking in relation to general intelligence. Ped. Sem., 1913, 2, 460-484.

(15) NicE, M. M.: Length of sentence as a criterion of a child's progress in speech. Jour. Educ. Psychol., 1925, 16, 370-379.

(16) Piaget, J.: The language and thought of the child. (Trans. by M. Warden) New York, Harcourt Brace, 1928, pp. 260.

(17) Romanes, George John: Mental Evolution in Man. D. Appleton Co., 1889 , pp. 452.

(18) Sмгтн, M. E.: An investigation of the development of the sentence and the extent of vocabulary in young children. University of Iowa. Studies in Child Welfare, 3, No. 5, Iowa City, 1926, pp. 92.

(19) Stern, W.: Psychology of early childhood up to the sixth year. (Trans. by A. Barwell from the 3rd edition) New York: Holt, 1924, pp. 557.

(20) Terman, Lewis H. et al.: Genetic Studies of Genius. 1. Stanford University Press, 1925. 